\title{
Por uma Nova Concepção Jurídica de Empresa no Marco da Sociedade do Risco: do lucro inconsequente à responsabilidade socioambiental
}

\author{
Adriana Campos ${ }^{1}$ \\ Daniel Piovanelli Ardisson ${ }^{2}$
}

Resumo: O presente artigo busca demonstrar a evolução do conceito jurídico de empresa à luz de dois marcos socioeconômicos históricos: a sociedade industrial do final do século XIX e a sociedade do risco contemporânea. Partindo de uma análise da teoria econômica e do direito comercial ao final do século XIX, expõe-se inicialmente que a noção jurídica de empresa então vigente, influenciada pelo capitalismo industrial, era definida por um viés econômico e se focava exclusivamente na maximização da eficiência produtiva e do lucro.

Palavras-chave: Empresa. Sociedade Industrial. Sociedade do Risco. Responsabilidade Socioambiental.

\begin{abstract}
This paper seeks to demonstrate the evolution of the legal concept of enterprise between two historical socio-economic milestones: the industrial society of the late nineteenth century and the contemporary risk society. Based on an analysis of economics and commercial law at the end of the nineteenth century, it is initially explained that the legal notion of enterprise then used, influenced by the industrial capitalism, was defined by an economic bias and focused itself exclusively in maximizing production efficiency and profit.
\end{abstract}

Key words: Enterprise. Industrial Society. Risk Society. Social and Environmental Responsibility.

1 Doutora em Direito Constitucional pela Universidade Federal de Minas Gerais. Professora da Faculdade de Direito da Universidade Federal de Minas Gerais. E-mail: adricamp@uol.com.br.

2 Mestrando em Direito pela Universidade Federal de Minas Gerais. E-mail: danpiovanelli@hotmail.com.

Recebido em: 26/02/2012.

Revisado em: 18/04/2012.

Aprovado em: 20/04/2012. 


\section{Introdução}

A palavra "empresa", apesar do que possa parecer, não é o tema central deste trabalho. Como tal, ela é mera representação simbólica de uma concepção, um conceito norteado pelo conhecimento e experiência humanos e consolidado ao longo do tempo.

Uma palavra não possui vida sem uma concepção. Esta, ao contrário, é capaz de produzir as mais profundas transformações e marcas no ser e na sociedade, por mais difícil que seja traduzi-la em palavras. Logo, não é a palavra em si, mas a ideia que com ela se concebe que possui relevância.

Mas não é só. Um conceito não é algo criado ou construído fora de contexto. Como a sociedade, ele é fruto de um processo de desenvolvimento histórico em constante marcha, informado, em cada passo, pelos pressupostos do período e da realidade experimentada.

Conceitos, assim como palavras, têm vida própria. Não é sem motivo que intelectuais de todos os tempos têm se preocupado em criar conceitos, adaptá-los e utilizá-los de forma cuidadosa e responsável, pois, como há muito já salientava Baruch de Espinosa (1973, p. 71) “[...] não se deve duvidar de que também as palavras, como a imaginação, podem ser a causa de muitos e grandes erros, se com elas não tivermos muita precaução".

É levando em consideração essa preocupação que a concepção jurídica de empresa é aqui abordada por dois marcos históricos: a sociedade industrial do final do século XIX e a sociedade do risco contemporânea. E, como se verá, não são poucas as consequências desse desenvolvimento histórico.

Usado desregradamente em um primeiro momento pela sociedade capitalista industrial em seu apogeu, o conceito em voga ajudou a produzir riquezas para uns, mas, também, riscos e tragédias para muitos.

Todavia, um amadurecimento inegavelmente associado ao desenvolvimento social e à (cons)ciência dos resultados do passado ajudou a que a concepção jurídica de empresa pudesse se tornar, hoje, algo mais, 
orientada não só pela promessa de capital, mas também pelos valores socioambientais reconhecidos.

O presente trabalho busca captar a transformação histórica do conceito ao longo dos marcos em que embasado, de forma a indicar não somente o ontem e o hoje, mas também um possível amanhã para a empresa no ordenamento jurídico e em si mesma.

\section{Acepção do Vocábulo Empresa}

A palavra empresa deriva do particípio passado do verbo imprehendere (imprehensu), e foi originalmente incorporada à língua italiana (imprésa). A filologia indica-lhe algumas acepções, dentre as quais vale a pena destacar a designação de determinada sociedade, do complexo de bens utilizado pela sociedade, ou da ação de empreender. (DUARTE, 2004, p. 54)

Durante toda a exposição que se segue, postas à parte as divergências de significado existentes, o vocábulo empresa será utilizado para descrever o ato ou efeito de empreender.

O uso específico que aqui se aponta tem, em si, um fim próprio. Como ação, ou resultado da ação, a empresa demanda necessariamente a conjunção de todos os outros elementos que a configuram, assim como o empresário e a sociedade. (BERTOLDI; RIBEIRO, 2009, p. 52-54)

Ademais, todo o processo de produção e circulação de bens e serviços, campo de interesse precípuo da economia e das teorias que lhe são relacionadas, passa a ser conjuntamente abordado.

\section{O Direito Comercial e a Empresa na Sociedade Industrial do Final do Século XIX}

Originalmente incorporado visando a regulamentar a atividade realizada entre os mercadores, o direito comercial surgiu da necessidade de manter a dinâmica da estrutura econômica então imperante. 
À época, o Direito Comercial era um direito de classe (CUCURELLA; AVILÉS, 1953, p. 39), e o foco da legislação se dava sobre os sujeitos envolvidos no ato de escambo praticado, porquanto a execução dos "atos de comércio", expressão então utilizada para definir os atos de circulação de bens a cargo dos comerciantes (RIPERT, 1972, p. 171-172), era a principal fonte de riqueza.

O processo de industrialização da produção, todavia, promoveu mudanças radicais na economia.

A circulação de bens, imediatamente ligada à atividade dos comerciantes, já não gozava de igual prestígio perante a ciência econômica, eis que a transformação industrial que se dera acabou por gerar um grande acúmulo de capital nas mãos dos detentores dos meios de produção.

Tamanhos foram os reflexos daí decorrentes que o próprio direito comercial, já ao início do século XIX, passou também por uma profunda transformação.

Como o comerciante já não se apresentava como a figura mais importante da atividade econômica, dividindo espaço com o produtor dos bens, os "atos de comércio", utilizados pelas legislações então vigentes, já não eram mais definidos por critérios exclusivamente subjetivos. (BAUDE, 1952, p. 10-17)

Além disso, algumas características do sistema subjetivo, tais quais a instituição de uma "jurisdição" exclusiva para uma casta especial de cidadãos (comerciantes), repugnavam os ideais da Revolução Francesa (que ocorrera havia pouco tempo), em especial o princípio da igualdade perante a lei. (CUCURELLA; AVILÉS, 1953, p. 40)

Consequentemente, a utilização exclusiva do sistema subjetivo fora abolida. Passou-se a fazer uso, em regra, de um sistema objetivo, amplamente difundido na Europa e vigente por todo o século XIX (ASCARELLI, 1940, p. 5-6), que definia os "atos de comércio" especialmente pela natureza do ato praticado.

A mudança, que perdurou do início do século XIX até meados do século XX, pode ser vista como um dos pressupostos remotos de criação 
da empresa, que apesar de não ser uma mera mutação daqueles "atos", absorveu-lhes as características.

Mas não é esta a única alteração promovida pelo processo de industrialização, que mudou a face do planeta.

O sistema capitalista, mostrando já sua força desde a Revolução Francesa, irradiou efeitos por todas as áreas e de tal forma que, ao defini-lo, Joseph Schumpeter (1961, p. 99) afirmou ter a sociedade burguesa configurado a si mesma, bem como seus alicerces e vigas, em moldes puramente econômicos. Segundo o economista, todas as estruturas do sistema “[...] se orientam para o lado econômico da vida. Recompensas e penalidades são oferecidas ou aplicadas em termos pecuniários. Elevar-se ou declinar na vida significa ganhar ou perder dinheiro".

Sedentos pela promessa de capital, os detentores dos meios de produção deram início a um processo de profundo desenvolvimento tecnológico, originalmente destinado a maximizar a eficiência produtiva e, consequentemente, o lucro daí advindo.

Ademais, já ao final do século XIX, além da franca expansão na elaboração de novas tecnologias voltadas para os meios de produção, a dinâmica do sistema econômico passou a ser moldada, outrossim, pela capacidade de criar novos e melhores produtos, aptos a satisfazerem as demandas dos consumidores.

Por certo, a legislação respeitava as bases do panorama que se apresentava, e corroborava a situação de absoluta liberdade de que dispunham os industriais e cientistas na criação de novas tecnologias.

Como aponta Tullio Ascarelli (1940, p. 6), os códigos do século XIX se inspiravam nos princípios do individualismo e do liberalismo econômico, e a influência deles se mostrava de maneira particularmente clara nos códigos de direito mercantil, que definiam os "atos de comércio" quase exclusivamente segundo sua relevância econômica. Que se dirá das constituições, ainda vistas como meras orientações organizativas da atuação do poder público.

Tal qual a legislação, os órgãos executivos seguiam as regras do liberalismo, e eram dessa forma ineficientes ou inativos em qualquer ten- 
tativa de arrefecer ou regulamentar as inovações tecnológicas. O economista Werner Sombart, ao descrevê-los, proferiu célebre frase segundo a qual "[...] capitalism rules the world and makes our statesmen dance like puppets on a string."3 (SOMBART apud BEAUD, 2001, p. 129)

É nesse plano de fundo que os "atos de comércio", definidos economicamente como atos de produção ou circulação de bens ou serviços e fontes de capital e de lucro (almejado sempre em maiores quantidades), assumem o posto de causa e consequência das especulações científicas e tecnológicas, feitas com nenhum ou pouco rigor metodológico e sem qualquer responsabilidade social e ambiental.

Ressalte-se que a situação não se limitou ao final do século XIX, em que se deu seu apogeu. Na verdade, ela foi fruto de um processo de transformações de quase um século, descrito por Michel Beaud (2001, p. 131) como "[...] a century of exploiting and sacking the planet; a century of accelerated industrialization, modernization, and the 'development of underdevelopment'; a century of imperialism."

Produtos e métodos produtivos perigosos, insumos poluentes e danos constantes causados a trabalhadores, consumidores e ao meio ambiente em geral: esse é o panorama encontrado ao final do século XIX e início do século XX em uma ordem econômica dominada pela busca incessante do lucro inconsequente ${ }^{5}$.

Para ilustrar, vale lembrar um trecho da obra de Joseph Schumpeter (1997, p. 86) ao definir, ainda que talvez não intencionalmente, a ideia que, no período em questão, regia a busca pela realização da empresa:

\footnotetext{
3 “[...] o capitalismo governa o mundo e faz nossos estadistas dançarem como fantoches em uma corda." (Tradução livre).

4 “[...] um século de exploração e saqueamento do planeta; um século de acelerada industrialização, modernização, e do 'desenvolvimento do subdesenvolvimento'; um século de imperialismo.” (Tradução livre).

5 A palavra "inconsequente", presente no título e alhures no artigo, foi em todas as ocasiões utilizadas sem a conotação negativa que dela também se pode extrair, buscando simplesmente demonstrar, à luz do espírito da época, a ausência de maiores reflexões sobre as consequências da atividade empresarial e de seus processos produtivos.
} 
Como a ação militar deve ser decidida numa dada posição estratégica, mesmo que todos os dados potencialmente obteníveis não estejam disponíveis, assim também na vida econômica a ação deve ser decidida sem a elaboração de todos os detalhes do que deve ser feito. Aqui o sucesso de tudo depende da intuição, da capacidade de ver as coisas de um modo que depois prove ser correto, mesmo que não possa ser estabelecido no momento, e da captação do fato essencial, descartando-se o não-essencial, mesmo que não seja possível prestar contas dos princípios mediante os quais isso é feito.

\section{Da Sociedade Industrial à Sociedade do Risco}

Ao despertar do século XX, o capitalismo industrial começava a experimentar os primeiros sinais de crise, provocada, em grande parte, pelo próprio funcionamento do sistema.

Cientes do que adviria se o mercado fosse deixado à própria sorte, tal como vinha ocorrendo, os Estados passaram a atuar de modo mais firme sobre a economia, pelo que surgem as primeiras configurações do que mais adiante se nominaria de Wellfare State.

Assim teve início o período intervencionista, marcado por atuações legislativas e governamentais de maior vigor sobre os Estados adeptos ao capitalismo. (PONT, 1974, p. 49-50)

Seguindo as características da época, que passariam a ditar a atuação dos Poderes do Estado, em 1942, a Itália, governada pelo ditador fascista Mussolini e em plena campanha militar, editou seu novo código civil, alterando substancialmente a dinâmica de tratamento da matéria comercial com a instituição da teoria da empresa.

Segundo Fábio Ulhoa Coelho (2005, p. 9), há de ter em mente o panorama político em que se deu o nascimento da teoria da empresa. Para o fascismo, a luta entre a burguesia e o proletariado terminaria em "[...] harmonia patrocinada pelo estado nacional". Os antagonismos seriam superados em vista dos objetivos superiores da nação, e a “[...] empresa, no 
ideário fascista, representa justamente a organização em que se harmonizam as classes em conflito."

Era na realização da empresa idealizada pelo fascismo que se daria a conformação social de duas classes, que, por cerca de um século, digladiaram-se sobre bases ideológicas contrapostas: o liberalismo capitalista e o marxismo comunista. E era desse modo que a empresa assumiria os primeiros contornos de uma instituição com finalidades sociais claras.

Todavia, o desenvolvimento do processo de conformação não se deu segundo o modelo fascista, em franca derrocada após o término da Segunda Guerra Mundial. Na verdade, foi a propagação de legislações trabalhistas cada vez mais protetivas, impulsionada por ideais marxistas amplamente difundidos entre o proletariado, que deu à empresa evidentes traços sociais.

Um segundo aspecto característico do período em questão é o surgimento dos primeiros efeitos, até então latentes, desencadeados pela expansão do sistema capitalista industrial-tecnológico de produção.

Até o início do século $\mathrm{XX}$, o sistema produtivo vigente resistira às tentativas frustradas de eticização promovidas. O lucro era a finalidade última da atuação humana. Mantinham-se as configurações sociais puramente sobre bases econômicas. No entanto, duas guerras mundiais e uma crise mercadológica sem precedentes (1929) forçaram o despertar gradual para o mundo que se houvera criado.

A primeira onda de conscientização se deu após a utilização de armas químicas na primeira guerra mundial e, principalmente, após a explosão das duas bombas atômicas em Hiroshima e Nagazaki na Segunda Guerra Mundial. Começava a se formar a ideia de que o mundo tal qual o conhecemos talvez não resistisse a uma terceira guerra global. O desenvolvimento industrial-tecnológico, que originalmente tentara se mostrar inofensivo e positivo, agora dava os primeiros sinais (nada discretos) de todo o seu potencial destrutivo. (BECK, 1998, p. 27)

Após a segunda guerra, surgem movimentos generalizados de identificação e reconhecimento dos direitos do homem, considerado em si 
mesmo e coletivamente, a exemplo da Declaração dos Direitos Humanos (1948). As constituições escritas a partir de então, auxiliadas pela atuação jurisprudencial dos tribunais constitucionais, assumem, enfim, o caráter político-normativo que possuem.

Entretanto, no mesmo período, motivados pelo processo de reconstrução do que se haviam tornado espólios de uma tragédia, os países se uniram em dois blocos distintos, de ideais simetricamente opostos: capitalistas e comunistas.

Engajados em uma corrida em que não haveria vencedor, apenas perdedores, ambos deram seguimento ao processo de explotação e exaurimento dos recursos naturais. Novas tecnologias eram criadas, à medida que o planeta se tornava, cada vez mais, um lixão onde se despejavam os restos e resíduos tóxicos e inservíveis dos processos produtivos.

Nesse imenso tabuleiro de xadrez das relações macroeconômicas, a empresa continuava a representar papel de absoluta relevância. Da menor das agulhas à mais complexa das armas, era por meio da empresa e de seus processos criativos que a nova face do mundo ia se apresentando cada vez mais deformada, mais cinza e áspera.

É nesse contexto que se dá a segunda onda de conscientização. A destruição então inerente à produção já não podia escapar aos olhos atentos de uma sociedade permanentemente alerta para o novo risco que se anunciava: uma terceira guerra mundial. É, igualmente, nesse período que se dão as primeiras tentativas de globalizar o intuito de proteção do meio ambiente e do planeta, a exemplo da Conferência das Nações Unidas sobre o Meio Ambiente Humano, realizada em Estocolmo em 1972. (MILARÉ, 2009, p. 1.190)

Fizeram-se enfim claros os riscos da atuação humana. À "modernidade", que dissolvera os contornos da sociedade industrial originada no início do século XIX (BECK, 1998, p. 16), sucedeu uma "segunda modernidade", em que se dá início a um processo de publicização dos riscos inerentes à atividade produtiva (BECK, 2003) e às consequências daí decorrentes, em especial, a uma releitura do conceito jurídico de empresa. 


\section{Uma Nova Concepção Jurídica de Empresa à Luz da Socieda- de do Risco}

A expressão "sociedade do risco", pela qual se define a mudança de paradigma que traz a lume uma nova concepção jurídica de empresa, não traduz uma quebra entre períodos históricos e sistemas socioeconômicos (BECK, 1998, p. 17). Na verdade, segundo afirma Ulrich Beck, ela é fruto do desenvolvimento coerente da modernidade "[...] más allá del proyecto de la sociedad industrial.” (1998, p. 17)

Todavia, para entendê-la com perfeição, primeiro se faz necessário definir o que se deve entender por risco.

\subsection{Definindo "risco"}

A palavra, tal qual utilizada pelo sociólogo e referenciada aqui, não visa a definir as consequências e danos que já se realizaram. Ao contrário, ela tem a ver essencialmente com a noção de previsão, ou seja, com a utilização dessa noção para a visualização de "[...] destrucciones que aún no han tenido lugar, pero que son inminentes, y que precisamente en este significado ya son reales hoy." (BECK, 1998, p. 39)

Ela define um estágio de quase realização dessas destruições, porquanto, caso não haja atuação humana apta a impedir o que se tinha por previamente estabelecido, seu devir é certo. Assim, os riscos abordados são, ao mesmo tempo, expressão de destruições e danos tanto ocorridos como não ocorridos, tudo a depender de como a sociedade se comporta a partir da ciência deles.

Como se vê, não são os riscos em si que dão ao período caracterização diversa da modernidade que o antecede, mas a (cons)ciência deles (BECK, 1998, p. 29). E esse processo de conscientização se dá em ordem inversa ao que ocorria nas situações de determinação de classes e camadas. Enquanto nelas o ser determina a consciência, nas situações de risco "[...] la conciencia determina al ser [...]", e o saber, em consequência, “[...] adquiere un nuevo significado político.” (BECK, 1998, p. 29) 
A consciência dos riscos, não obstante, torna-se de certa forma uma consequência natural do próprio processo de desenvolvimento pelo qual passaram.

Ao contrário do que acontecia no século XIX e primeira metade do século $\mathrm{XX}$, riscos empresariais e profissionais

[...] ya no se limitan a lugares y grupos, sino que contienen una tendencia a la globalización que abarca la producción y la reproducción y no respeta las fronteras de los Estados nacionales, con lo cual surgen unas amenazas globales [...] (BECK, 1998, p. 19)

Outrossim, àquele tempo, os perigos eram perceptíveis pelos sentidos, enquanto os riscos civilizatórios hoje "[...] se sustraen a la percepción y más bien residen en la esfera de las fórmulas químico-físicas [...]" (BECK, 1998, p. 28)

Resumindo, os riscos, produtos globais “[...] de la maquinaria del progreso industrial [...]" agravados pelo subsequente desenvolvimento (BECK, 1998, p. 28), levam abaixo as bases com que as forças produtivas foram pensadas e sobre as quais se atuou até agora, e a sociedade passa a se determinar de modo diverso a partir da (cons)ciência deles.

\subsection{Uma Sociedade Dominada Pelos Riscos}

Influenciada pelo liberalismo e individualismo que marcavam o capitalismo em seu auge, na sociedade industrial a ideia de produção de riquezas dominava a ideia de produção de riscos, e estes, apesar de se concretizarem regularmente em danos efetivos, não se anunciavam de modo suficientemente forte a ponto de subverter a lógica do sistema.

Já na sociedade do risco essa relação se inverte. A ganância por riquezas geradas pelo progresso técnico-econômico se vê ofuscada cada vez mais pela (cons)ciência da geração dos riscos. Já não se pode mais legitimá-los sob a categoria de "efectos secundarios latentes", porquanto sua "[...] universalización, crítica pública e investigación (anti)científica [...]" revelam o que até então se fizera imperceptível (BECK, 1998, p. 
19): os riscos são frutos da atuação humana, e, em especial, de processos produtivos inconsequentes.

Esta mudança na relação de prioridade entre a lógica da produção e distribuição de riqueza e a lógica da produção e distribuição do risco (BECK, 1998, p. 200) altera também o espaço sociopolítico ocupado pela empresa.

Na sociedade industrial do século XIX, ela atuara sob o vácuo legislativo e governamental, gozando de ampla liberdade para criar e experimentar. Já na sociedade "moderna" que perdurou do início do século XX até a década de setenta, marcada por atuações legislativas e governamentais mais intensas, as atividades técnico-econômicas ainda não se encontravam efetivamente incluídas nos processos de discussão e legitimação democrática. A empresa atuava na esfera "subpolítica", a partir da qual influenciava todo o processo direta e eficazmente, embora sofresse regulação política apenas aparente. (BECK, 1998)

Logo, apesar da regulação política (pouco ou nada eficaz) e da vulnerabilidade às decisões macroeconômicas tomadas pelo Poder Público, a definição dos rumos da empresa era deixada à livre iniciativa e à lógica dos investimentos privados, pois temia-se que uma politização efetiva desse sistema pudesse burocratizá-lo em demasia e, consequentemente, reduzir a marcha do progresso.

O processo de publicização e politização da empresa, todavia, adquire claros contornos políticos na sociedade do risco. A partir dela, "[...] lo que hasta el momento se había considerado apolítico se vuelve político [...]”. A opinião pública e a política “[...] empiezan a mandar en el ámbito íntimo del management empresarial, en la planificación de la producción, en el equipamiento técnico, etc." (BECK, 1998, p. 29-30)

Enfim, em um momento inicial, socialmente afetado pela descoberta dos riscos, a discussão dos contornos da empresa não é mais deixada exclusivamente à iniciativa privada. Funcionando como antitese para a tese que vigia na sociedade industrial, de vácuo político, a empresa é alçada ao patamar de processo público político. 


\subsection{A Proposta de Ulrich Beck}

Segundo Beck (1998, p. 282-285), o processo de politização das discussões, acima indicado, faz com que a política, em um primeiro momento, veja-se carente de centro e de direção, e, consequentemente, sem uma noção precisa de sua tarefa frente à empresa.

Isso não deve ser visto somente sob um aspecto negativo, na medida em que, a partir dele, a rígida diferenciação funcional " [...] comporta y se desactiva por desdiferenciaciones (conflictos y cooperaciones debidos a los riesgos, moralización de la producción, diferenciación de la subpolítica)." (BECK, 1998, p. 286)

Todavia, essa politização, característica na sociedade do risco, também não deve ser feita exageradamente, sob pena de a política se tornar a instância última de todos os debates e regulamentações.

Assim, propõe o sociólogo que a atividade técnico-econômica deve adentrar a política oficial, mas de maneira discreta e limitada, de modo que, se comparado "[...] con el núcleo de la subpolítica, se pasaría al predominio de un efecto de la política conservador." (BECK, 1998, p. 289)

A proposta por ele realizada de adequação da empresa à sociedade do risco pode ser lida e sintetizada a partir de três ângulos diversos, um interno e outros dois externos à atividade técnico-econômica.

Em primeiro lugar, o desenvolvimento de uma atuação autocrítica é essencial para que a empresa possa internalizar o paradigma constitucional pluralista que norteia as sociedades contemporâneas e se pautar a partir dele. Assim, faz-se necessário garantir institucionalmente o fornecimento de uma via de reflexão paralela ao predomínio da gestão empresarial, via essa apta a permitir o acesso a “[...] expertos alternativos, prácticas profesionales alternativas, controversias internas en la empresa y en la profesión acerca de los riesgos implícitos en los desarrollos objeto del escepticismo reprimido.” (BECK, 1998, p. 288)

Já em âmbito externo, inicialmente, é imprescindível que se deem condições prévias para a existência e o desenvolvimento de juízos independentes e de intervenções decididas e independentes dos meios de co- 
municação, “[...] dos pilares fundamentales para el sistema del control alternativo de la subpolítica [...]” (BECK, 1998, p. 288)

Ademais, à política cumpre [...] establecer las condiciones generales (legalmente), examinar el carácter general de las normativas y suscitar el consenso" (BECK, 1998, p. 289), bem como proteger os direitos sociais já alcançados, inclusive contra suas próprias influências.

Logo, demanda-se uma (re)análise sistemática de todo o conjunto normativo, de modo que nem mesmo as leis, ou sua interpretação isolada (fruto do positivismo), possam subverter o parâmetro jurídico-constitucional obtido.

Apesar da ordem de exposição do raciocínio, que segue o desenvolvimento do sociólogo, é fácil perceber a lógica de retroalimentação em que a releitura da concepção jurídica de empresa é feita, porquanto parte da abstração jurídico-constitucional ao âmbito concreto dos processos produtivos e àquela retorna.

A seguir, essa releitura é desenvolvida levando-se em consideração o ordenamento jurídico brasileiro.

\subsection{A Empresa Reinterpretada à Luz da Sociedade do Risco e do Ordenamento Jurídico-Constitucional Brasileiro}

Constitucionalmente garantida, a livre iniciativa (BRASIL, 1988) concede aos cidadãos o direito à escolha e ao exercício da empresa elegida. Esta, cujo conceito específico só pode ser obtido por meio da leitura do art. 966 do Código Civil Brasileiro (BRASIL, 2002), é definida como a "[...] atividade econômica organizada para a produção ou a circulação de bens ou de serviços".

Afora a limitação promovida pelas próprias implicações conceituais relativas à filologia do vocábulo, que não se propõe a conceituar toda e qualquer atividade, a empresa escolhida encontra óbices e delimitações maiores ainda na esfera constitucional.

Logo, embora a Constituição de 1988 garanta, no art. 1 $^{\circ}$, inciso IV, a livre iniciativa como um dos fundamentos da República Federativa do Brasil, ela também prevê, no caput do art. 225, que todos têm direito ao 
meio ambiente ecologicamente equilibrado, essencial à sadia qualidade de vida, motivo pelo qual incumbe não só ao Poder Público como também à coletividade defendê-lo e preservá-lo para as presentes e futuras gerações. (BRASIL, 1988)

Uma atividade que tenha por finalidade conquistar lucro a qualquer preço, ainda que por meio da destruição ambiental e da imposição de riscos e danos à sadia qualidade de vida, já não pode ser concebida juridicamente como empresa, pois a norma legal que a define se submete não só ao art. $1^{\circ}$, inciso IV da Constituição, como também ao caput do art. 225 da Lei Fundamental. (BRASIL, 1988)

A empresa já não é só a “[...] atividade econômica organizada para a produção ou a circulação de bens ou de serviços [...]", mas sim a “[...] atividade econômica organizada para a produção ou a circulação de bens ou de serviços [...]" (BRASIL, 2002) que defenda e preserve, para as presentes e as futuras gerações, o meio ambiente equilibrado, essencial à sadia qualidade de vida. (BRASIL, 1988)

O desenvolvimento hermenêutico de uma nova concepção jurídica de empresa, tal qual o realizado logo acima, não pode, igualmente, ficar alheio às previsões normativas encontradas nos art. 170, inciso VI, e art. 225, $§ 1^{\circ}$, incisos IV e V, da Constituição da República. (BRASIL, 1988)

A primeira prevê que a ordem econômica tem como princípio a defesa do meio ambiente, "inclusive mediante tratamento diferenciado conforme o impacto ambiental dos produtos e serviços e de seus processos de elaboração e prestação". Já as outras duas estabelecem que incumbe ao poder público, respectivamente, exigir estudo de impacto ambiental para as obras ou atividades que apresentem potencial de degradação ambiental, bem como "[...] controlar a produção, a comercialização e o emprego de técnicas, métodos e substâncias que comportem risco para a vida, a qualidade de vida e o meio ambiente." (BRASIL, 1988)

Assim, a empresa, para ser concebida juridicamente como tal na atualidade, não pode se limitar ao exercício inconsequente da "[...] atividade econômica organizada para a produção ou a circulação de bens ou de serviços" (BRASIL, 2002). Ela deve, em igual medida, defender e pre- 
servar o meio ambiente equilibrado, essencial à qualidade de vida, bem como se sujeitar a estudos de impacto ambiental, caso apresente potencial de degradação ambiental, a tratamento diferenciado, conforme o impacto ambiental decorrente de seus processos produtivos, e ao controle de sua produção, comercialização e emprego de técnicas, métodos e substâncias que possam representar risco para a vida, para o meio ambiente e para a qualidade deles.

É, portanto, já na caracterização constitucional da empresa dentro do ordenamento jurídico brasileiro que se mostram as primeiras evidências da diferença, deveras óbvia, entre a empresa que teve lugar na sociedade industrial do final do século XIX e a empresa tal como vista perante a sociedade do risco contemporânea. Enquanto aquela era definida juridicamente de modo rígido e por um viés exclusivamente econômico, esta apresenta natureza mais ampla, flexível, e porta consigo uma extensa carga jurídico-axiológica socioambiental.

Ressalte-se que raciocínio parecido pode ser feito utilizando-se não só as demais normas dispostas na Constituição, mas também as normas legais positivas que tenham o intuito de garantir os valores socioambientais alcançados. Isso se deve em razão da sistematicidade com que o ordenamento se organiza. Logo, caso a atividade técnico-econômica, na consecução de sua finalidade, seja desenvolvida por meio da violação de uma norma legal de segurança do trabalho, seu enquadramento como empresa passa a ser inadequado à luz da releitura jurídico-constitucional que aqui se propõe.

Contudo, esse é apenas o primeiro ponto de desenvolvimento de uma nova concepção jurídica da empresa à luz da sociedade do risco. Tal como dito por Ulrich Beck e já exposto anteriormente, se o controle da atuação que se dá na esfera subpolítica demanda juízos e meios de comunicação independentes, as normas que disciplinam as garantias judiciais e a liberdade de imprensa assumem um importante significado.

Logo, diante de situações em que se contraponham, de um lado, os princípios e regras de livre condução da empresa, se e como produtora de riscos socioambientais, e de outro os princípios e regras de garantia 
da atuação independente dos juízos e da imprensa, estes últimos devem prevalecer.

Por fim, talvez a proposição mais ousada e de maior relevância do sociólogo seja a de que as pessoas envolvidas na empresa devem buscar internalizar, no âmbito das decisões, um paradigma pluralista, que permita o exercício da reflexão a respeito dos próprios processos criativos e produtivos.

Tal qual o macrossistema político, jurídico-constitucionalmente organizado no Brasil de modo a permitir a participação de diferentes representações da sociedade no processo de debate e escolha dos rumos a serem tomados, a empresa assim definida passaria a funcionar como um microcosmos constitucional, uma minirrepresentação do sistema constitucional pluralista de decisão.

Assim, o controle dos processos produtivos, insumos e demais elementos que possam representar riscos socioambientais viria não apenas de entes externos, mas também daqueles que fazem parte da atividade em si, e que, como tal, têm mais informações e, consequentemente, melhores condições de orientar e guiar a empresa segundo os padrões jurídico-constitucionalmente permitidos.

\section{Conclusões}

O art. 966 do Código Civil Brasileiro buscou definir a empresa de modo parecido àquele vigente já ao final do século XIX, ou seja, como a "[...] atividade econômica organizada para a produção ou a circulação de bens ou de serviços.” (BRASIL, 2002)

Não obstante, já não se pode mais pensá-la como algo esparso e exclusivamente econômico. É o que mostra Ulrich Beck (1998, p. 19), segundo quem a (cons)ciência dos riscos gerados no processo de busca inconsequente por lucros fez a lógica das prioridades se alterar.

É no risco, e não na riqueza, que a sociedade tem se pautado para atuar. E o ordenamento jurídico brasileiro não pode ficar alheio a essa inversão. 
A empresa já não é só uma atividade. Ela é uma atividade responsável. Não é só um processo. É um processo sustentável. Ela deve se pautar, em toda a sua extensão, pela responsabilidade socioambiental reconhecida pela Constituição (a exemplo dos art. 170, inciso VI e art. 225, caput e $\S 1^{\circ}$, incisos IV e V) (BRASIL, 1988) e pelas leis por ela informadas.

Poder Judiciário e imprensa possuem, igualmente, importante papel nesse novo sistema que se anuncia e que começa já a se mostrar presente. Como entes de controle da iniciativa privada, eles devem atuar de modo independente e com prioridade, sempre que se faça necessário frear os abusos cometidos e resguardar os valores socioambientais constitucionalmente visados.

Por fim, o âmbito interno de decisão sobre o exercício da empresa demanda uma reformulação. Esse âmbito deve refletir, na medida do possível, o modelo constitucional pluralista que norteia o macrossistema político, permitindo que as decisões a serem tomadas passem por filtros democráticos de contraposições, opiniões e ideias, aptos a promoverem o desenvolvimento do processo produtivo e um controle mais eficaz de eventuais riscos socioambientais que se fizerem presentes.

\section{Referências}

ASCARELLI, Tullio. Derecho mercantil. México, D.F.: Porrua Hnos y Cia., 1940.

BAUDE, Jules. Principes de droit appliqué aux affaires. Bruxelles, Belgique: Les Editions Comptables, Commerciales et Financières, 1952.

BEAUD, Michel. A history of capitalism: 1500-2000. New York, USA: Monthly Review Press, 2001.

BECK, Ulrich. La sociedade del riesgo: hacia una nueva modernidad. Barcelona, España: Paidós, 1998.

. Liberdade ou capitalismo: Ulrich Beck conversa com Johannes Willms. Trad. Luiz Antônio Oliveira de Araújo. São Paulo: Editora UNESP, 2003. 
BRASIL. Constituição da República Federativa do Brasil de 1988. Disponível em: <http://www.planalto.gov.br/ccivil_03/constituicao/ constitui\%C3\%A7ao.htm>. Acesso em: 23 jul. 2011.

. Lei n. 10.406, de 10 de janeiro de 2002. Institui o Código Civil. Disponível em: <http://www.planalto.gov.br/ccivil_03/leis/2002/L10406. htm>. Acesso em: 23 jul. 2011.

COELHO, Fábio Ulhoa. Manual de direito comercial. 16. ed. São Paulo: Saraiva, 2005.

CUCURELLA, Gabriel Avilés; AVILÉS, José M. Pou de. Derecho mercantil. Barcelona, España: José M. Bosch, 1953.

DUARTE, Ronnie Preuss. Teoria da empresa: à luz do novo Código Civil Brasileiro. São Paulo: Método, 2004.

ESPINOSA, Baruch de. Tratado da correção do intelecto. São Paulo: Abril S.A. Cultural e Industrial, 1973 (Os pensadores, v. 17).

MACHADO, José Pedro. Dicionário etimológico da língua portuguesa, v. 2. Lisboa: Horizonte, 1977.

MILARÉ, Édis. Direito do ambiente: a gestão ambiental em foco. Doutrina. Jurisprudência. Glossário. 6. ed. São Paulo: Editora Revista dos Tribunais, 2009.

PONT, Manuel Broseta. Manual de derecho mercantil. Madrid, España: Editorial Tecnos, 1974.

RIPERT. Georges. Traité elementaire de droit commercial. 7. ed. Paris, France: Libraire Générale de Droit et de Jurisprudence, 1972.

SCHUMPETER, Joseph Alois. Capitalismo, socialismo e democracia. Trad. Ruy Jungmann. Rio de Janeiro: Editora Fundo de Cultura, 1961. . Teoria do desenvolvimento econômico: uma investigação sobre lucros, capital, crédito, juro e o ciclo econômico. Trad. Marília Silvia Possas. São Paulo: Editora Nova Cultural, 1997. 